\title{
First illustrated description of the male of Diphya macrophthalma, the type species of the genus (Araneae, Tetragnathidae)
}

\author{
Yuri M. Marusik1-3 \& Mikhail M. Omelko4,5
}

\author{
1. Institute for Biological Problems of the North RAS, Portovaya Str. 18, Magadan, Russia. (yurmar@mail.ru) \\ 2. Department of Zoology \& Entomology, University of the Free State, Bloemfontein 9300, South Africa. \\ 3. Zoological Museum, Biodiversity Unit, Fl-20014 University of Turku, Finland. \\ 4. Far Eastern Federal University, Sukhanova 8, Vladivostok 690950, Russia. \\ 5. Federal Scientific Center of the East Asia Terrestrial Biodiversity FEB RAS, 690022 Vladivostok, Russia.
}

Received 20 April 2017

Accepted 21 June 2017

DOI: $10.1590 / 1678-4766 e 2017036$

\begin{abstract}
Diphya macrophthalma Nicolet, 1849, a type species of the genus and known by only holotype female from Central Chile, is redescribed in details based on recently collected material. The male is described in details and illustrated for the first time. Diphya rugosa Tullgren, 1902 previously considered as junior synonym of D. macrophthalma is revalidated. The known distribution of Diphya species from southern South America is mapped. Comments about status of northernmost populations of D. spinifera Tullgren, 1902 are given.
\end{abstract}

KEYWORDS. Aranei, South America, Chile, Argentina, revalidisation.

Nicolet (1849) described Diphya from Central Chile. He placed four new species in the genus and all were collected in Valdivia Province. All species descriptions are brief and lack illustrations. SimON (1889) was first who revised this genus. He synonymised all species with Diphya macrophthalma Nicolet, 1849, because of page priority, due to lack of types of all other species and due to insufficient descriptions. SimON (1889:218) mentioned that types are lost, but not commented how he acquired a single specimen. In the consequent paper dealing with Diphya, Simon (1894) fixed type species, D. macrophthalma and described a "tribe" Diphyeæ Simon, 1894 with Diphya and Dolichognatha O. Pickard-Cambridge, 1869. Besides Simon $(1889,1894)$ affinities of genus were considered in TULLGREN (1901, 1902), TanikaWa (1995) and Álvarez-Padilla \& Hormiga (2011). Currently 14 species are known in the genus Diphya (MARUsIK, 2017), but so far only two species are illustrated in detail, namely $D$. spinifera Tullgren, 1902 from Chile (see Álvarez-Padilla \& Hormiga 2011) and Diphya wulingensis Yu, Zhang \& Omelko, 2014 from Far East Asia (see MArusiK et al., 2017). The type species remains known only from the brief descriptions by NiCOLET (1849) and SimON (1889) and three figures of epigyne by TULLGREN (1902) and TANIKAWA (1995). Existing figures do not show internal structure of the epigyne. Recently, Kirill Eskov collected half a dozen of specimens of both sexes belonging to Diphya from three provinces adjacent to Valdivia (Fig. 35). Two of these provinces early were considered as part of Valdivia (Fig. 36).
Epigyne of this species well fit in shape and size to those given by TANIKAWA (1995: f. 17) and belonging to the specimen considered by Simon as D. macrophthalma. Both males and females well correspond to the description given to all four Nicolet's species, due to presence of light median stripe on carapace. Since the male of this species was never illustrated, along with endogyne and habitus of both sexes, a decision was made to redescribe this species. Brief comments on Chilean species are made and known distribution of the genus in Chile and Argentina is provided.

\section{MATERIAL AND METHODS}

Specimens were photographed with a Canon EOS 7D camera attached to an Olympus SZX16 stereomicroscope. Scanning electron images were taken with a SEM JEOL JSM-5200 scanning microscope at the Zoological Museum, University of Turku, Finland. Digital images were montaged using CombineZP image stacking software. Epigyne was cleared in a $\mathrm{KOH} /$ water solution until soft tissues were dissolved. Photographs were taken in dishes with cotton or paraffin on the bottom to hold the specimens in position. All specimens will be deposited in the Zoological Museum of Moscow State University (curator K.G. Mikhailov). All measurements are given in $\mathrm{mm}$.

Abbreviations used in the text: ALE, anterior lateral eyes; AME, anterior median eyes; PLE, posterior lateral eyes; PME, posterior median eyes; $d$, dorsal; $p$, prolateral; $\mathrm{r}$, retrolateral. 


\section{TAXONOMY}

\section{Diphya Nicolet, 1849}

Diphya Nicolet, 1849:406; Simon, 1894:744; Tullgren, 1902:24; TANIKAWA, 1995:102; Álvarez-PAdilla \& Hormiga, 2011:756.

Type species: Diphya macrophthalma Nicolet, 1849 from central Chile, designated by Simon (1894).

Diagnosis. Diphya is one of the best delimited genera of Tetragnathidae due to eye pattern and spination of legs I and II. ALE as well as posterior eyes are greatly enlarged and at least 2 times larger than AME (vs. all eyes equal in size, or if sizes heterogeneous, lateral eyes are smallest). In addition to large size, the lateral eyes in Diphya are widely spaced. This character (spaced lateral eyes) is known in only a few Tetragnatha, were all eyes are of equal size. Another character that allows Diphya to be separated from other tetragnathids is retrolateral row of stiff subdecumbent setae on legs I and II (Figs 1, 2, 4, 8) forming kind of capturing basket. Males of species occurring in Chile and Argentina can be distinguished from all other Tetragnathidae by having tibial apophysis (Figs 9, 12, 14, 16-18).

\section{Diphya macrophthalma Nicolet, 1849}

(Figs 1-30, 33-35)

Diphya macrophthalma NiCOLET, 1849:406(q); SIMON, 1889:217; 1894:744; TANIKAWA, 1995:106, f. 17 ( 9 ). Syntype $q$ examined after photographs provided by A. Tanikawa (for specimen details see TANIKAWA, 1995:106). Diphya crassipes NicOLET, 1849:406 (q).

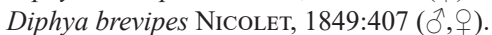

Diphya longipes NicOLET, 1849:407 (ठ゚).

Material examined. CHILE: Los Rios Region, Osorno: Ō, N. P. Puyehue, Anticura Sector, ca. 40³9'13”S $72^{\circ} 15^{\prime} 45^{\prime} \mathrm{W}$, edge of Nothofagus forest, anthropogenic meadow, 10.01.2014 (K. Eskov, R. Rakitov). Los Lagos Region: Llanquihue: $q$, N. P. Alerce Andino, boggy Phigerodendron forest, in Sphagnum, 5-11.01.2014 (K. Eskov); Chiloé: $2 \hat{\jmath}$, + , Chiloé Isl., Senda Darwin Biol. Station, boggy Baccharis matorral, in moss and sweeping, 30.01-7.02.2014 (R. Rakitov); 9 , same locality, dates and collector, Nothofagus-Podocarpus forest, in Sphagnum.

Note. In the first half of 19 th century two provinces, Osorno and Llanquihue, now belonging to different administrative regions were considered as parts of Valdivia Province, and therefore two of six specimens treated here were collected in "terra typica" and four other were collected in neighboring Chiloé Province.

Diagnosis. Male of D. macrophthalma well differs from other species occurring in southern South America by having straight tibial apophysis (bent in other species). Females of $D$. macrophthalma can be distinguished by lack of septum, longitudinal fovea and rectangular median plate (vs. septum present, fovea transversal if present, and round or inverted trapezoidal median plate (cf. TANIKAWA, 1995, figs 18, 20-22).
Description. Male. Total length 2.75, carapace 1.38 long, 1.10 wide. Carapace yellowish with white median band and brownish sides of thoracic part (Fig. 6). Eyes surrounded with wide black rings. Eyes very large except AME (Figs 5-6), which are about 2 times smaller than others; black rings around AME and ALE touching each other, lateral eyes spaced by more that 1 diameter, posterior eye row wider than anterior one; PME spaced by less than 1 diameter. Clypeus yellow about 1.5 of AME diameter or 1 diameter of ALE. Chelicerae brown, darker near fangs, with 3 prolateral and 4 retrolateral teeth. Sternum brown with dark brown margins; labium and maxillae dark brown. Femora brown without spots. Tibiae and metatarsi with grayish spots at top and middle part. Tibia-tarsi of legs I and II with row of stiff inflexible setae forming catching basket. Legs size, number and position of macrosetae shown in Tabs I, II. Abdomen whitish, dorsum with folium composed by bright white spots and stripes and dark stripes and bands. Lateral sides of abdomen black with white longitudinal stripes near dorsum. Ventral side of abdomen yellowish with gray longitudinal band. Epigastrum with about 2 dozens of epiandrous fusules (Fig. 34). Colulus with few setae (Fig. 35).

Palp as in Figs 9-15, 16-21. Femur as long as patella and tibia, about 4 times longer than wide; patella cylindrical, with long dorsal macrosetae about 2 times longer than patella; tibia subconical with wider distal part, with long cylindrical dorso-retrolateral apophysis (Da); distal part of tibia with 4 long macrosetae; cymbium with prolateral hollow (rounded cut off) (Figs 12, 16); paracymbium complex with bilobate ventral part $(\mathrm{Pv})$ and spine like dorsal part $(\mathrm{Pd})$; ventral lobe of ventral part larger dorsal and bears five macrosetae; bulb oval in lateral view; tegulum (Tg) ribbon like; conductor (Co) lamellar twisted around axis together with embolus, embolus proper (Em) with wide accompanying membrane (Am) heavily sclerotized ventrally (Ev).

Female. Total length 4.28, carapace 1.8 long, 1.35 wide. Carapace like in male. Sternum brown with dark brown margins (Fig. 3). Legs I and II like in males with prolateral row of stiff setae. Legs size, number and position of macrosetae shown in Tabs III, IV. Abdomen white without distinct pattern, with median stripe lacking guanine spots; posterior part with almost indistinct dark lateral spots; venter with more distinct pattern, composed by 2 parallel dark stripes in the middle, and dark lateral bands laterally, number and size of guanine spots fewer than in dorsum.

Epigyne as in Figs 22-30, epigynal plate 1.4 wider than high, with well delimited by furrow (Ef) oval central plate $(\mathrm{Pc})$ and marginal plate $(\mathrm{Pm})$, marginal plate thin on lateral sides and wide in anterior part, anterior edges with kind of pockets (Ap) well distinct in macerated epigyne; central plate with square shape median plate $(\mathrm{Mp})$ and small longitudinal fovea (Fo); anterior part of median plate with hollow and pit (Pi); anterior part of fovea with one copulatory opening $(\mathrm{Oc})$; copulatory ducts $(\mathrm{Cd})$ diverging posteriorly; receptacles with two chambers, large posterior ( $\mathrm{Rp}$ ) and smaller anterior ( $\mathrm{Ra})$. Anterior part of anterior chamber covered with accessory glands appeared as pit (Pi) with 1-3 cilia (Gc). 


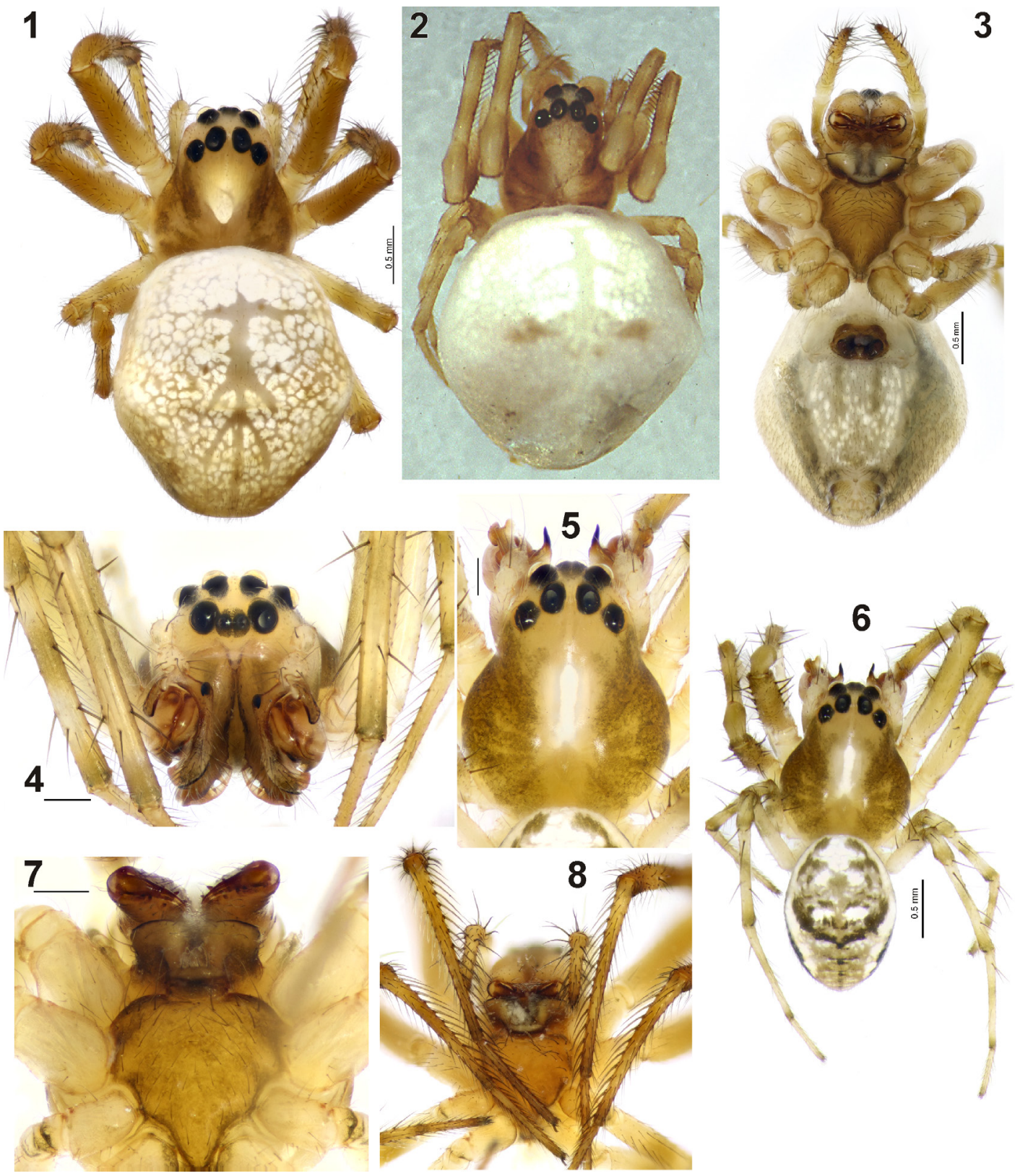

Figs 1-8. Somatic characters of Diphya macrophthalma Nicolet, 1849: 1, 2, female habitus, dorsal; 3, female habitus, ventral; 4, 5, male prosoma, frontal and dorsal; 6, male habitus, dorsal; 7, male prosoma, ventral; 8, female prosoma, ventral. Fig. 2, holotype, made by Tanikawa. Scale $=0.2 \mathrm{~mm}$ if not otherwise indicated.

Tab. I. Legs segments length in ô of Diphya macrophthalma Nicolet, 1849.

\begin{tabular}{ccccccc}
\hline & Femur & Patella & Tibia & Metatarsus & Tarsus & Total \\
\hline I & 1.70 & 0.60 & 1.58 & 1.95 & 0.98 & 6.80 \\
II & 1.53 & 0.54 & 1.28 & 1.44 & 0.78 & 5.57 \\
III & 0.95 & 0.30 & 0.63 & 0.68 & 0.45 & 3.00 \\
IV & 1.35 & 0.30 & 0.90 & 0.99 & 0.53 & 4.07 \\
\hline
\end{tabular}

Tab. II. Spination of legs in ô Diphya macrophthalma Nicolet, 1849.

\begin{tabular}{ccccc}
\hline & Femur & Patella & Tibia & Metatarsus \\
\hline I & $1(0) \mathrm{d}, 4 \mathrm{p}, 6 \mathrm{r}$ & $1 \mathrm{~d}$ & $2 \mathrm{~d}, 3 \mathrm{p}, 2 \mathrm{p}$ & - \\
II & $2 \mathrm{~d}, 3(4) \mathrm{p}, 5 \mathrm{r}$ & $1 \mathrm{~d}$ & $1 \mathrm{~d}, 2 \mathrm{p}, 2 \mathrm{r}$ & - \\
III & $2(3) \mathrm{d}$ & $2 \mathrm{~d}$ & $1 \mathrm{p}, 1 \mathrm{r}$ & $1 \mathrm{~d}, 2 \mathrm{p}$ \\
IV & $3 \mathrm{~d}, 1 \mathrm{p}, 1 \mathrm{r}$ & $2 \mathrm{~d}$ & $2 \mathrm{~d}, 1 \mathrm{p}, 1 \mathrm{r}$ & $1 \mathrm{~d}, 1 \mathrm{p}$ \\
\hline
\end{tabular}




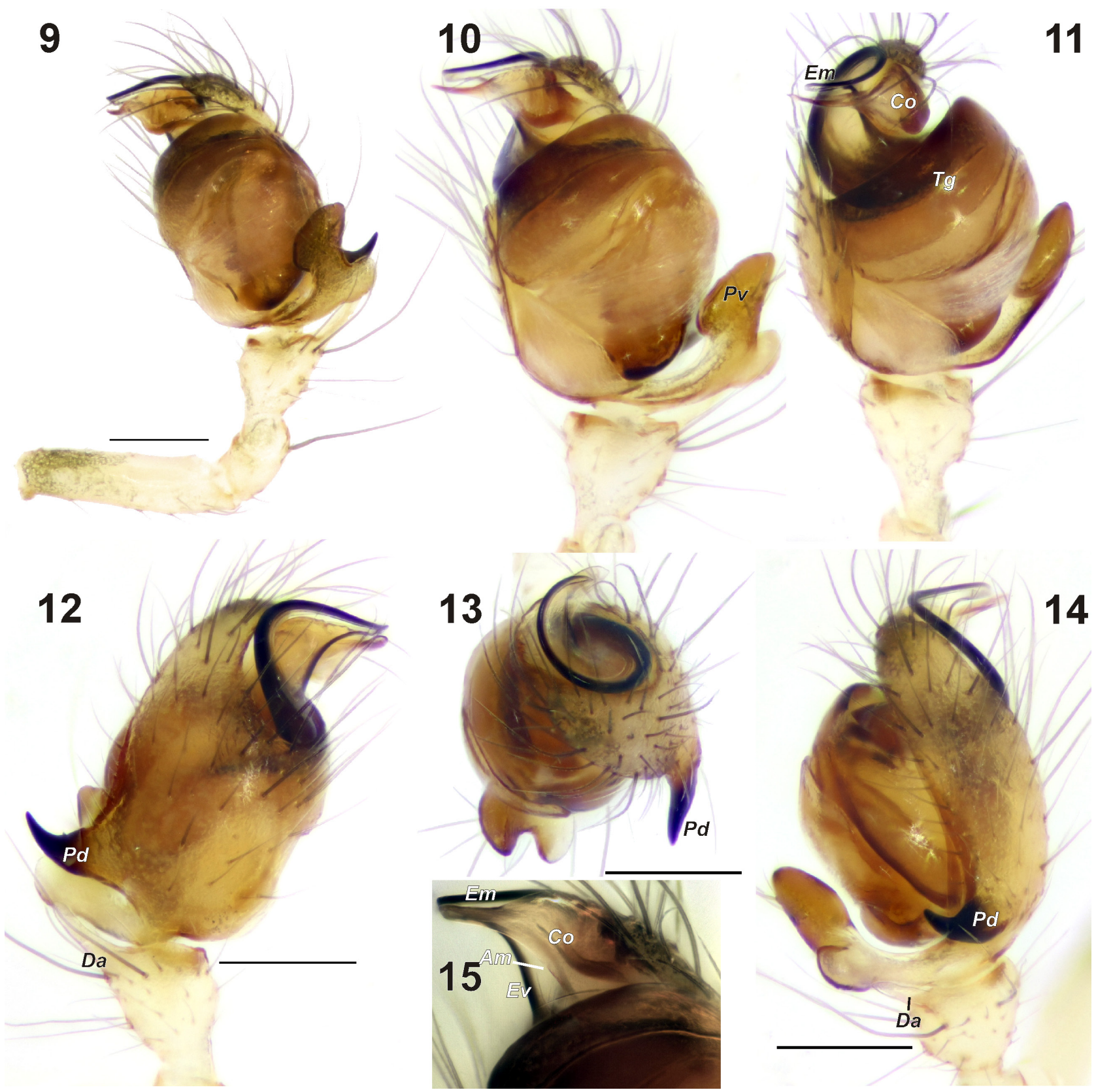

Figs 9-15. Male palp of Diphya macrophthalma Nicolet, 1849: 9, whole palp, retrolateral; 10, 11, terminal part of palp, retro-ventral and antero-ventral; 12, same, prolateral; 13, 14 same, anterior and dorsal; 15, terminal part of the bulb, retrolateral (Am, accompanying membrane; Co, conductor; Da, dorso-retrolateral apophysis; Em, embolus; Ev, embolus ventrally; Pd, spine like dorsal part; Tg, tegulum). Scale = $0.2 \mathrm{~mm}$.

Tab. III. Legs segments length in 9 of Diphya macrophthalma Nicolet, 1849.

\begin{tabular}{ccccccc}
\hline & Femur & Patella & Tibia & Metatarsus & Tarsus & Total \\
\hline I & 1.82 & 0.75 & 1.68 & 1.65 & 0.83 & 6.72 \\
II & 1.58 & 0.69 & 1.35 & 1.41 & 0.83 & 5.85 \\
III & 1.02 & 0.45 & 0.71 & 0.75 & 0.53 & 3.45 \\
IV & 1.44 & 0.45 & 1.02 & 0.98 & 0.62 & 4.50 \\
\hline
\end{tabular}

Tab. IV. Spination of legs in 9 of Diphya macrophthalma Nicolet, 1849.

\begin{tabular}{ccccc}
\hline & Femur & Patella & Tibia & Metatarsus \\
\hline I & $2 \mathrm{p}$ & $1 \mathrm{~d}$ & $2 \mathrm{p}, 1 \mathrm{r}$ & - \\
II & - & $1 \mathrm{~d}$ & $1 \mathrm{~d}, 2 \mathrm{p}, 1(2) \mathrm{r}$ & - \\
III & - & $1 \mathrm{~d}$ & $1 \mathrm{p}, 1 \mathrm{r}$ & $1 \mathrm{~d}, 1 \mathrm{p}$ \\
IV & - & $1 \mathrm{~d}$ & $1 \mathrm{~d}, 1 \mathrm{p}$ & $1 \mathrm{p}$ \\
\hline
\end{tabular}



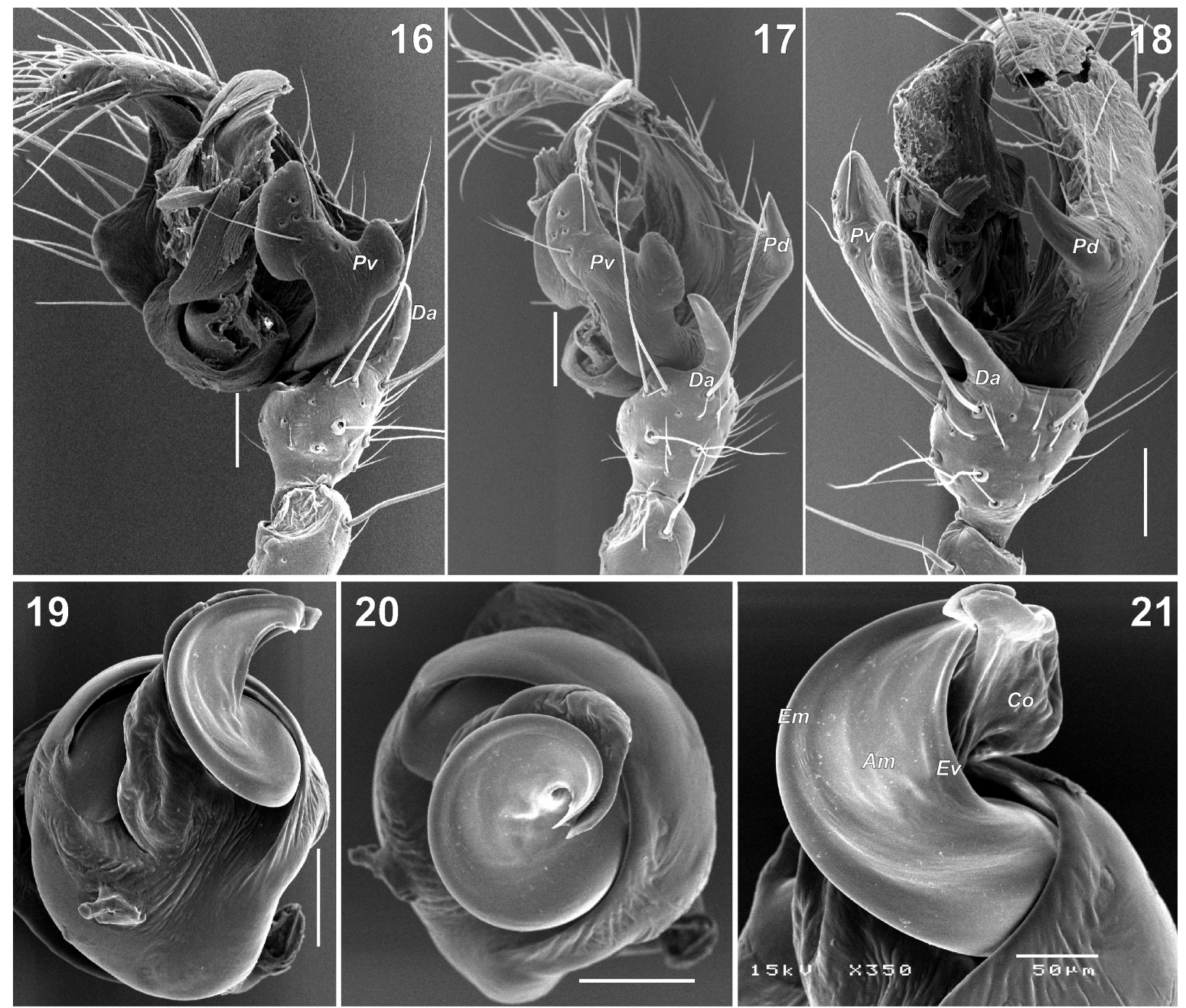

21
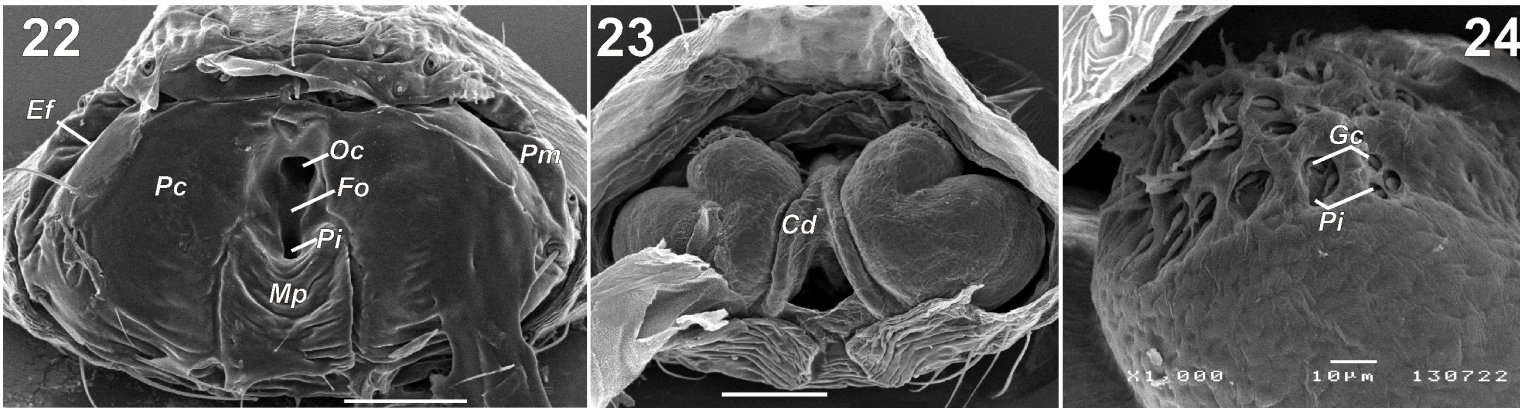

Figs 16-24. Male palp and epigyne of Diphy a macrophthalma Nicolet, 1849: 16, 17 terminal part of palp with removed bulb, ventro-retrolateral, retrolateral and dorso-retrolateral; 19-21 bulb, dorsal, anterior and prolateral-anterior; 22 epigyne, ventral; 23 epigyne, dorsal; 24 anterior chamber of receptacle with glands (Am, accompanying membrane; Co, conductor; Cd, copulatory ducts; Da, dorso-retrolateral apophysis; Em, embolus; Ef, epigynal furrow; Ev, embolus ventrally; Fo, fovea; Gc, gland cilia; Mp, median plate; Oc, copulatory opening; Pc, central plate; Pd, dorsal part of paracymbium; Pi, pit; Pm, marginal plate. Scale $=0.1 \mathrm{~mm}$ if not otherwise indicated.

Shape of fovea, pit and copulatory opening well visible in SEM photographs only. Holotype female and 3 examined females with mating plug $(\mathrm{Pl})$ inside fovea. Size of plug vary from small (Fig. 25) to large (Fig. 26).

Variations. White median stripe on carapace in one of three females almost indistinct. In all three males examined white stripe is distinct. Venter of abdomen vary from uniformly white to with distinct pattern as shown on Fig. 3. Size variation: male, total length 2.53-2.75, carapace 1.35-1.43 long; female, total length 3.88-4.28, carapace 1.63-1.93 long. NiCOLET (1845) indicated size of D. macrophthalma holotype as 1.5 lines which corresponds to $3.2 \mathrm{~mm}$ or $3.8 \mathrm{~mm}$ (depends if counted line as $1 / 12^{\text {th }}$ or $1 / 10^{\text {th }}$ of the inch), while SIMON (1889) mentioned that it is $4.5 \mathrm{~mm}$ long.

Distribution. So far it is known in four localities in Central Chile (Fig. 36). 

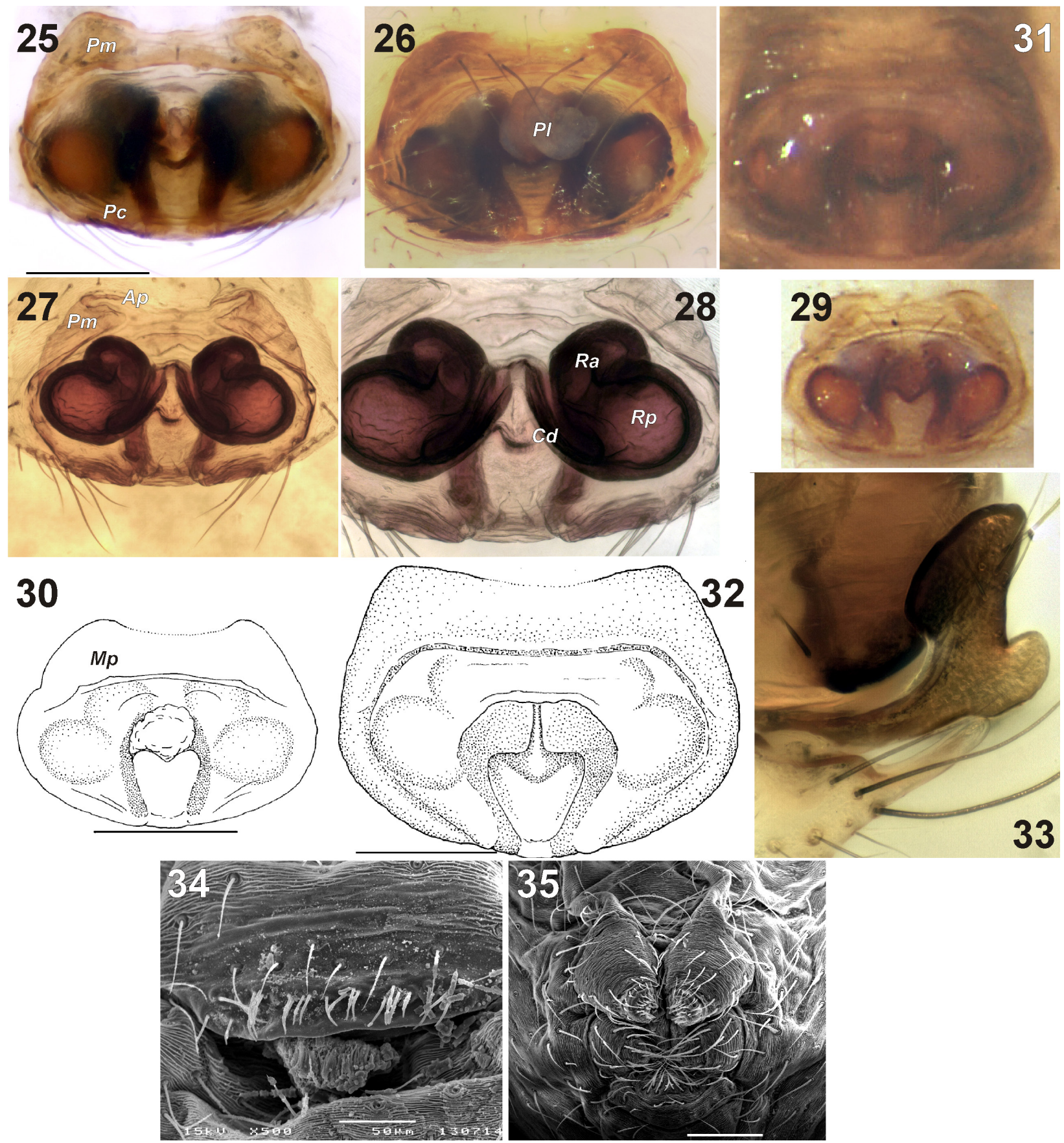

Figs 25-35. Diphya macrophthalma Nicolet, 1849 (Figs 25-30, 33-35) and D. rugosa Tullgren, 1902 (Figs 31, 32): 25, 26, 29-32 epigyne, ventral; 27, 28 epigyne, dorsal; 33 paracymbium and tibia, ventro-retrolateral; 34, male epigastral area showing epiandrous spigots; 35, male spinnerets; 29,30 holotype; 31, 32 syntype. Figs 30, 32 after TANiKaWa (1995). Figs 29, 31 made by A. Tanikawa (Ap, anterior pockets; Cd, copulatory ducts; Pc, central plate; Pl, mating plug; Pm, marginal plate; Ra, anterior chambers of receptacles; Rp, posterior chambers of receptacles).

\section{Diphya rugosa Tullgren, 1902, revalidated}

(Figs 31, 32, 36)

Diphya rugosa TullgRen, 1902:31, pl. 3, f. 3 (). Syntype $q$ examined after photographs provided by A. Tanikawa (for specimen details see TANIKAWA, 1995:106).

Diphya macrophthalma: TANIKAWA, 1995:106, f. 18 ( 9 , synonymised two species).
Comments. Diphya rugosa was described based on three specimens from Valley of Aysén River belonging currently to Aysén Province, Chile. TANIKAWA (1995) was first to examined the types. Because of some similarities in shape of median plate of epigyne, and presence of mating plug in epigyne of D. macrophthalma hiding fovea, he considered two species as synonyms. Comparisons made in this study, 


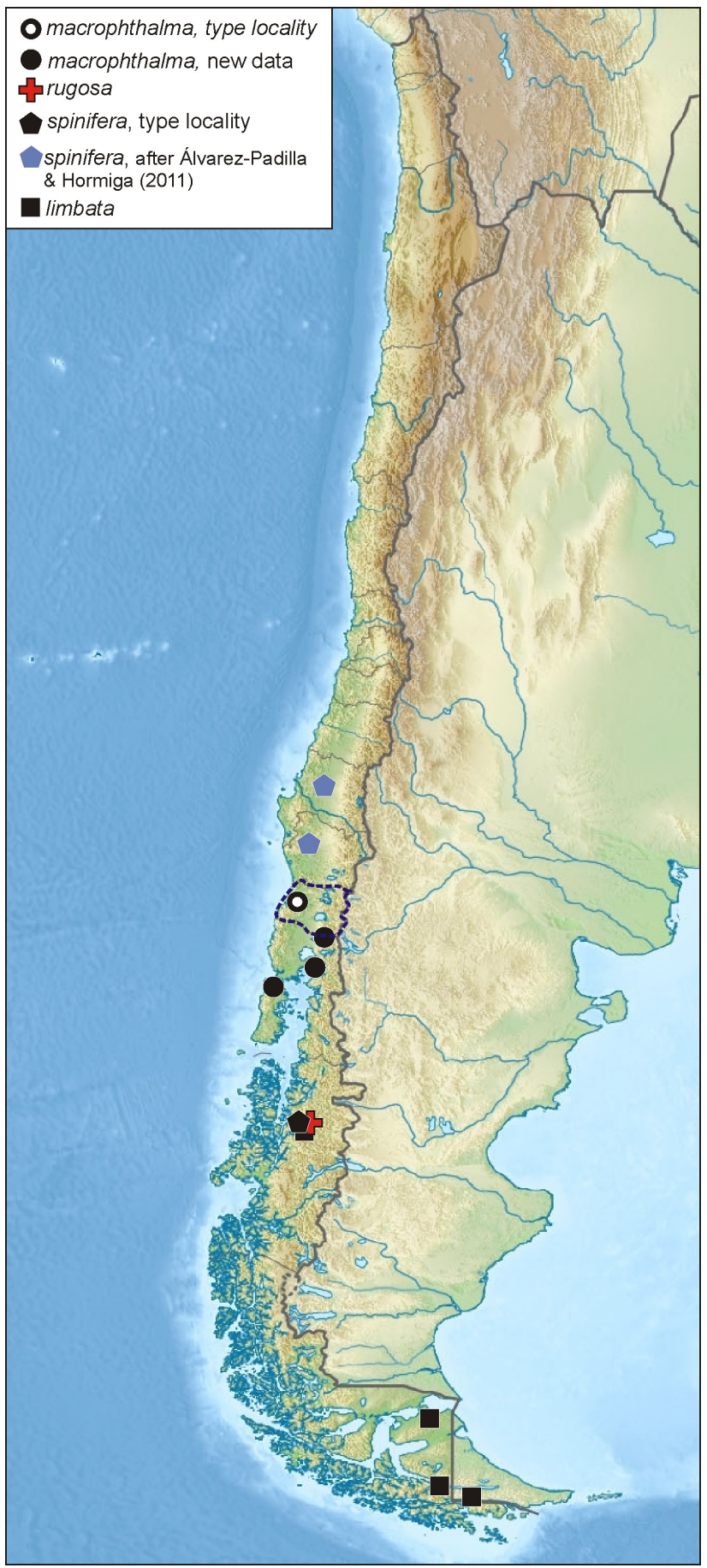

Fig. 36. Distribution of Diphya species known in Chile and Argentina.

show that the epigyne of $D$. rugosa and D. macrophthalma (figs 18 and 17 respectively in Tanikawa, 1995) differ in size (respectively Figs 32,30). It is clear that the epigyne of the former species is larger and the marginal plates well differ in shape. After maceration of epigyne of D. macrophthalma, it became clear that species is lacking a septum, which is present in D. rugosa. In addition, the type localities of the two species are separated by over $600 \mathrm{~km}$ (see Fig. 36).

\section{Diphya spinifera Tullgren, 1902}

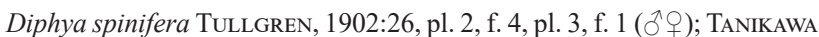
1995:110, f. 22, 25-26 (ð, Р).

Diphya spinifera: Álvarez-Padilla \& Hormiga 2011:756, f. 26A-G, $27 \mathrm{~A}-\mathrm{G}, 28 \mathrm{~A}-\mathrm{F}, 29 \mathrm{~A}-\mathrm{G}, 30 \mathrm{~A}-\mathrm{C}(\hat{\jmath}$, +$)$ possibly misidentified.

Comments. The species was described from the same locality as the previous one, from Valley of Aysén River. Mapping distribution of Chilean Diphya we recognized that specimens of $D$. spinifera examined and illustrated in details by Álvarez-PADilla \& Hormiga (2011) were collected far from the type locality (about $900 \mathrm{~km}$ to the north). Comparison of the figures of epigyne in TANIKAWA (1995, fig. 22) made from the syntype of $D$. spinifera and that made by Álvarez-Padilla \& Hormiga (2011, 28a and $30 \mathrm{c}$ ) from northern specimens reveals that the females from distant localities have different proportions of median plate of epigyne (semicircular in syntype and circular in northern specimens). Figures of the male palp also differ in Tanikawa (1995) and Álvarez-Padilla \& Hormiga (2011), but interpretation of such differences is not possible, because it seems that lamella accompanied embolus is not illustrated in TANIKAWA (1995). It is very likely that specimens examined by Álvarez-PADILla \& Hormiga (2011) represent undescribed species.

Acknowledgements. We thank Kirill Y. Eskov (Moscow, Russia) who gave us material used in this study. Special thanks to Akio Tanikawa (Tokyo, Japan) for consultations and giving us photographs made from type material of Diphya macrophthalma and D. rugosa, and some other species. Seppo Koponen kindle allowed us to sue Museum facilities in Turku and help to arrange our stay in Turku. English of the earlier draft was kindly checked by Robin Lyle (Queenswood, South Africa). This project was supported in part by the grant from the President of the Russian Federation (MK-6046. 2016.4)

\section{REFERENCES}

Álvarez-Padilla, F. \& Hormiga, G. 2011. Morphological and phylogenetic atlas of the orb-weaving spider family Tetragnathidae (Araneae: Araneoidea). Zoological Journal of the Linnean Society 162:713-879.

MARUsIK, Y.M. 2017. A review of Diphya (Araneae: Tetragnathidae) from South Africa. Arthropoda Selecta 26(2):133-138.

Marusik, Y. M.; Omelko, M. M. \& Koponen, S. 2017. First record of Diphya wulingensis (Aranei, Tetragnathidae) in Russia. Arthropoda Selecta 26(2):139-144.

NiCOLET, A. C. 1849. Aracnidos. In: GAY, C. ed. Historia física y política de Chile, Zoología 3:319-543.

Simon, E. 1889. Etudes arachnologiques. 21e Mémoire. XXX. Descriptions de quelques arachnides du Chili et remarques synonymiques sur quelques unes des espèces décrites par Nicolet. Annales de la Société Entomologique de France (6) 8:217-222.

SimON, E. 1894. Histoire naturelle des araignées. Paris 1, p. 489-760.

TANIKAWA, A. 1995. Two new species of the spider genus Diphya (Araneae: Tetragnathidae) from Japan and Taiwan, with notes on the known species. Acta Arachnologica 44:101-111.

Tullgren, A. 1901. Contribution to the knowledge of the spider fauna of the Magellan Territories. In: Svenska Expeditionen till Magellansländerna 2(10):181-263.

Tullgren, A. 1902. Spiders collected in the Aysen Valley by Mr P. Dusén. Bihang till Kungliga Svenska Vetenskaps-Akademiens Handlingar 28(4;1):1-77. 